\title{
En mann i 40-årene med hodepine og tåkesyn
}

\author{
Hodepine med økt celletall i spinalvæsken, feber og meningeal fortyk- \\ kelse gir umiddelbare assosiasjoner til bakteriell meningitt. Ved sub- \\ akutt symptomdebut og atypisk sykdomsforløp med dårlig respons på \\ antibiotika skal imidlertid differensialdiagnostiske muligheter vurderes. \\ Vi omtaler en mann i 40-årene med alvorlige komplikasjoner til en \\ sjelden meningeal tilstand.
}

Engelsk oversettelse på www.tidsskriftet.no

Se kommentar side 1357

\section{Agnes Balint Bjørke* \\ agnes.bjorke@gmail.com \\ Christoph Michael Wahl \\ Nevrologisk avdeling \\ Synøve Kalstad \\ Revmatologisk avdeling

\author{
* Nåværende adresse: \\ Nevrologisk avdeling \\ Drammen sykehus
} \\ Vestre Viken}

Universitetssykehuset Nord-Norge

Pasienten hadde hatt residiverende otitter og episoder med behandlingsresistent sinusitt. Han var ellers frisk fra tidligere. Under en flytur til Spania utviklet han venstresidig øreverk og ble behandlet for mistenkt otitt ved et lokalt legekontor. Etter noen dager fikk han tiltakende global hodepine, talevansker og parestesier $i$ høyre kroppshalvdel, senere også væsking fra venstre øre. MR caput tatt på sykehus i Spania viste væske i mastoidceller samt en brem over venstre hemisfære tolket som kronisk subduralt hematom. Pasienten ble behandlet konservativt.

Kroniske subdurale hematomer kan oppstå spontant eller etter traume. Alkoholmisbruk og behandling med antikoagulantia er blant de disponerende faktorene. Kroniske subdurale hematomer gir noen ganger lite symptomer og kan hos eldre debutere med gradvis tiltakende forvirring. Vår pasient hadde verken opplevd et traume eller brukt antikoagulantia. Væsking fra øret er heller ikke et typisk symptom ved kronisk subduralt hematom.

Etter hjemreise til Norge, tre uker etter symptomdebut utviklet pasienten tåkesyn på høyre øye og ble innlagt ved Universitetssykehuset Nord-Norge. Ved innkomst forelå det lett redusert allmenntilstand. Pasienten hadde betydelig redusert syn på høyre øye, øresus $i$ venstre øre og lett dysartri. Omfattende blodprøvescreening viste senkning på $74 \mathrm{~mm} / \mathrm{h}(2-12 \mathrm{~mm} / \mathrm{h})$, CRP på $83 \mathrm{mg} / \mathrm{l}$ 1<5 mg/l) og lett forhøyet c-ANCA (S-AntiPR3) på $12 \mathrm{U} / \mathrm{ml}$ (negativ: $0-10 \mathrm{U} / \mathrm{ml}$, positiv: 11-530 U/mll, men ellers normale funn. Ved spinalvæskeanalyse fant man lett pleocytose med hvite blodceller på $29 \cdot 10^{6} / \mathrm{l} \quad<5 \cdot 10^{6} / \mathrm{ll}$ og totalprotein på $686 \mathrm{mg} / \mathrm{l} /<500 \mathrm{mg} / \mathrm{l}$ ). Apningstrykket ved lumbalpunksjon varnormalt. Øyelege konkluderte med optikusinfarkt på høyre øye. $\emptyset$ Øre-nese-hals-legen fant crustedanning $i$ venstre nesekavitet, og det ble mistenkt lekkasje av cerebrospinalvæske fra venstre øre. Infeksiøst agens ble ikke påvist $i$ noen av kroppsvæskene (blod, cerebrospinalvæske, øresekret, nasopharynx og urin). MR caput viste væskebrem med hevelse og kontrastopptak i meningene over venstre hemisfære samt væske iområde av mastoid på venstre side (fig 1a-c). Dette ble tolket som sannsynlig meningeal effusjon. Det ble konkludert med bakteriell meningitt, og pasienten ble satt på antibiotika.

Bakteriell meningitt er oftest et akutt sykdomsbilde med høy feber, hodepine og redusert bevissthet. Fokale nevrologiske utfall kan for eksempel skyldes meningoencefalitt, økt intrakranialt trykk eller sekundær vaskulitt. Epileptiske anfall kan forekomme. Celletallet i cerebrospinalvæsken er vanligvis sterkt forhøyet, og infeksiøst agens kan ofte påvises i cerebrospinalvæske eller blodkultur. Bakteriell meningitt kan oppstå via hematogen spredning av bakterier, men også ved lokal spredning, eksempelvis ved otitt, etter åpent hodetraume eller nevrokirurgiske inngrep. Hos vår pasient kunne væsking fra øret tale for otogen meningitt, men de kliniske symptomene debuterte subakutt og celletallet i cerebrospinalvæsken var svært lavt.

Det ble antatt at lavt celletall i spinalvæsken skyldtes at pasienten var forbehandlet for otitt med orale antibiotika. Pasienten ble også undersøkt av nevrolog, som konkluderte med atypisk subakutt meningitt som blant annet kunne gi mistanke om autoimmune meningittsyndromer, eksempelvis hypertrofisk pakymeningitt. Antibiotikabehandlingen for mistenkt bakteriell meningitt, utgått fra otitt (eventuelt mastoiditt), ble likevel gjenopptatt. I tillegg ble pasienten behandlet med deksametason og fikk innsatt ventilasjonrør $i$ venstre øre. Etter 2 1/2 ukers sykehusopphold og betydelig bedring $i$ tilstanden ble han utskrevet til hjemmet.

Behandling med steroider i akuttfasen av bakteriell meningitt på grunn av infeksjon med pneumokokker er veletablert, likeså ved tuberkuløs meningitt. Sekundær vaskulitt kan også respondere på slik behandling. Hos vår pasient var det nå vanskelig å avgjøre om bedringen skyldtes antibiotika eller steroidbehandlingen.

Nye episoder med global hodepine av pressende karakter, CRP-stigning og sensoriske symptomer i høyre kroppshalvdel samt epileptiske anfall i de kommende tre ukene førte til to reinnleggelser med nye antibiotikakurer og oppstart av antiepileptisk medikasjon. Gjentatte cerebrospinalvæskeanalyser viste uendrede funn, infeksiøst agens i cerebrospinalvæsken eller andre kroppsvæsker kunne ikke påvises. MR-kontroll viste økende venstresidig kortikalt hjerneødem. Med tanke på mulig epi- eller subduralt empyem ble det utført eksplorativ kraniotomi med meningeal biopsi. Makroskopisk fant man normalfarget, men hard og tykk dura samt leddblødende subduralt granulasjonsvev. Histologi viste fortykket dura med fibrose og uspesifikt inflammatorisk infiltrat (fig 2). Mikrobiologiske undersøkelser var normale. I et tverrfaglig møte der infeksjonsmedisiner, nevrolog, øre-nese-hals-lege, øyelege, revmatolog, nevrokirurg, nevroradiolog og nevropatolog deltok, ble det konkludert med at pasientens symptomer mest sannsynlig var betinget $i$ intrakranial hypertrofisk pakymeningitt.

Pasienten gjennomgikk en omfattende utredning. Man fikk avkreftet differensialdiagnostiske muligheter som er nevnt i litteraturen (fig 3), med unntak av Wegeners granulo- 

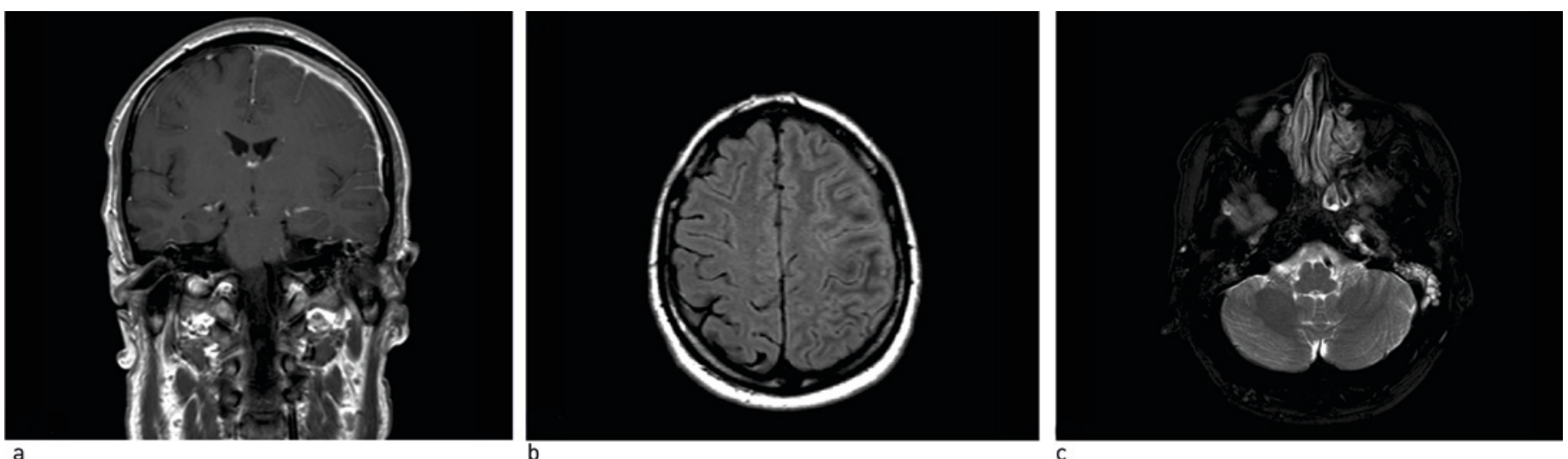

Figur 1 MR caput. al T1-sekvens med kontrast. Hevelse i meningene over venstre hemisfære med kontrastopptak. b) T2-sekvens. Fortykkede meninger på venstre side samt signalforandringer i tilgrensende hjerneparenkym. c) T2-sekvens, FLAIR. Væske i område av mastoid, rundt arteria carotis interna og vena jugularis ved skallebasis på venstre side

matose som ikke sikkert kunne utelukkes. Den videre utredningen ble derfor rettet mot dette. Det eneste positive funnet var c-ANCA som var svakt positiv initialt, men senere innenfor referanseområdet. Blodprøver for øvrig var normale. Det ble ikke funnet hudforandringer, hjerte- eller nyreaffeksjon. CT av tinningbein viste væske og bløtdelsfortykkelse i mellomøret og fortettede mastoidalceller på venstre side. Ved CT av bihuler så man hypoplastisk venstre maksillærsinus med slimhinnefortykkelse og væskespeil, men ingen granulomer. Biopsi av respiratorisk slimhinne konkluderte med uspesifikk kronisk betennelse, og ingen vaskulitt eller granulomer. CT thorax viste mulig progresjon av én av de små uspesifikke nodulære fortetningene som ble påvist i venstre overlapp ved sykdomsdebut, men forandringen var ikke tilgjengelig for biopsi (fig 4).

Det ble altså ikke funnet klare holdepunkter for underliggende sykdom, verken Wegeners granulomatose eller annen tilstand, og pasienten ble behandlet for en antatt idiopa- tisk intrakranial hypertrofisk pakymeningitt. Det ble gitt høydose Solu-Medrol i fem dager, deretter peroral administrering med $80 \mathrm{mg} \times 1$ i seks uker, med langsom nedtrapping. Denne behandlingen førte til regresjon av både symptomer og forandringer på MR.

Hypertrofisk pakymeningitt er en sjelden tilstand karakterisert ved aseptisk, kronisk inflammasjon som forårsaker pakymeningeal fortykkelse. Etter innføringen av CTog MR-teknologi har slike tilfeller blitt rap-
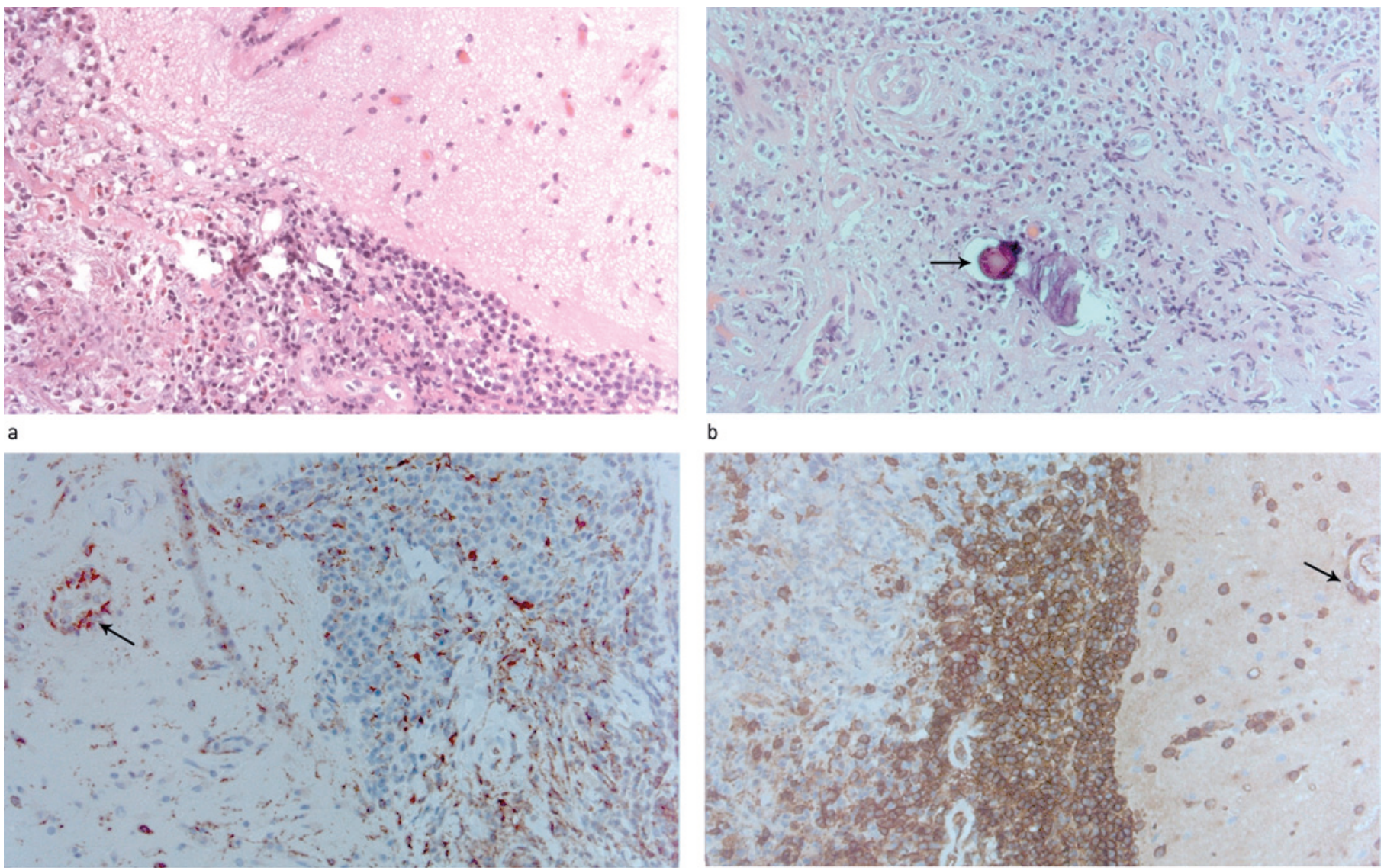

b

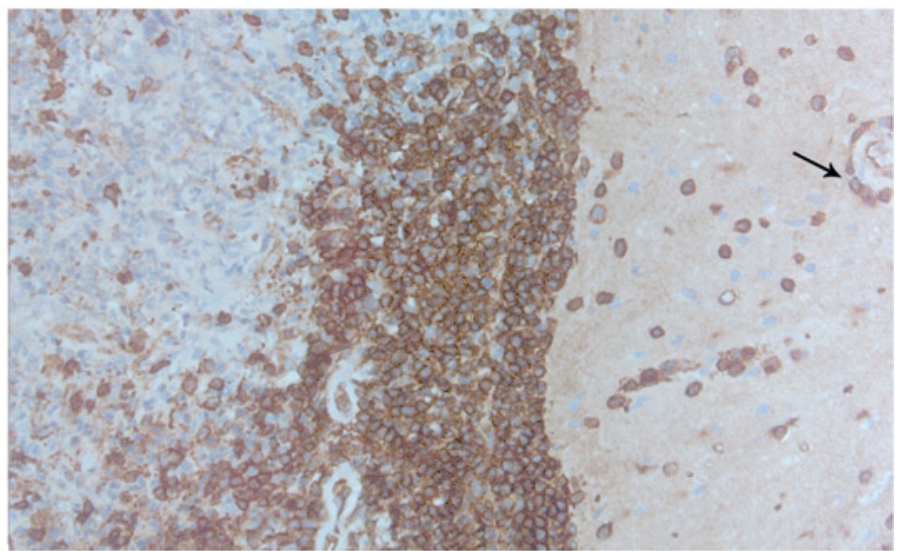

d

Figur 2 Biopsi av dura frontalt på venstre side. Histopatologisk undersøkelse viser fortykket dura med fibrose og uspesifikt inflammatorisk infiltrat. al Infiltrat med eosinofile granulocytter, plasmaceller og makrofager (H\&E× 20). b) Lymfohistiocytært infiltrat med psammomlegeme (pil) (H\&E $\times 20)$. c) Pilen peker på hjernevev (immunhistokjemi med makrofagantistoff $\times 20$ ). d) Pilen peker på hjernevev med lymfocytter rundt kar (immunhistokjemi med lymfocyttantistoff $\times 20$ ) 
portert oftere, men det foreligger ikke god kunnskap om forekomsten. Tilstanden ble først beskrevet av Charcot og Joffroy i 1869 , som påviste forandringer i spinale meninger. De tidlige beskrivelsene var relatert til tuberkulose eller syfilis (1). Siden er det blitt funnet en rekke årsaker som kan føre til inflammatorisk fortykkelse av dura mater, inkludert andre infeksjoner (soppinfeksjon), autoimmune systemsykdommer (revmatoid artritt, Wegeners granulomatose), nevrosarkoidose og neoplasmer $(2,3)$ (fig 3).

Eksklusjon av eventuell tilgrunnliggende patologi er viktig, men kan være vanskelig. Hvis en grundig utredning ikke avdekker systemisk årsak til meningeal fortykkelse, anses tilstanden som idiopatisk (4-7). Den idiopatiske formen forekommer meget sjelden. Gjennomsnittsalder ved debut er 50 år, med en variasjon på 20-80 år $(5,6)$. Det kliniske bildet ved intrakranial hypertrofisk pakymeningitt er uspesifikt og varierende. Hodepine, progressiv affeksjon av multiple hjernenerver og ataksi er de vanligste symptomene og manifesterer seg hhv. i ca. $90 \%$, $60 \%$ og $30 \%$ av tilfellene $(4,5,8)$. Epileptiske anfall forekommer også (9). Hodepinen kan være fokal eller diffus og kan være det eneste symptomet i flere år $(10$, 11). Hodepinen karakteriseres som kronisk daglig hodepine og likner ofte på kronisk migrene (12). I mange av de rapporterte tilfellene påvises det ikke forhøyet intrakranialt trykk, og hodepinen er da trolig relatert til meningeal inflammasjon.

Under nedtrapping av steroidbehandlingen til 30 mg daglig fikk pasienten på ny symptomer og nyoppstått diplopi. Det ble påvist høyresidig ekstern oftalmoplegi med affeksjon av oculomotorius-, trochlearis- og abducensinnervert muskulatur.

Pasienten hadde også klaget over nummenhet tilsvarende ophthalmicusgrenen fra nervi trigemini over affiserte øye. Hodepinen var nå mest lokalisert til høyre tinningregion opp mot pannen. Ny MR caput og regranskning av tidligere MR caput viste retrospektivt væske og bløtdelsoppfylning rundt venstre arteria carotis interna og vena jugularis under skallebasis (fig 1c). Tilstanden ble oppfattet som Wegeners granulomatose, med svakt positiv c-ANCA, slimhinnefortykkelse i bihuler, små nodulære fortetninger $i$ lunger, ekstern oftalmoplegi med affeksjon av flere øyemuskler og nummenhet i panne selv om ingen biopsifunn bekreftet diagnosen. Pasienten ble overflyttet til revmatologisk avdeling. På grunn av sykdommens alvorlighetsgrad ble han behandlet med intravenøs cyklofosfamid i seks måneder, med planlagt overgang til metotreksat som vedlikeholdsbehandling. Ved evaluering etter endt cyklofosfamidbehandling ble det imidlertid ved ny MR caput påvist økende fortykkelse av meningene, og pasienten ble gitt rituximab. Han har hatt god respons på denne behandlingen. Det er til nå gitt tre behand-

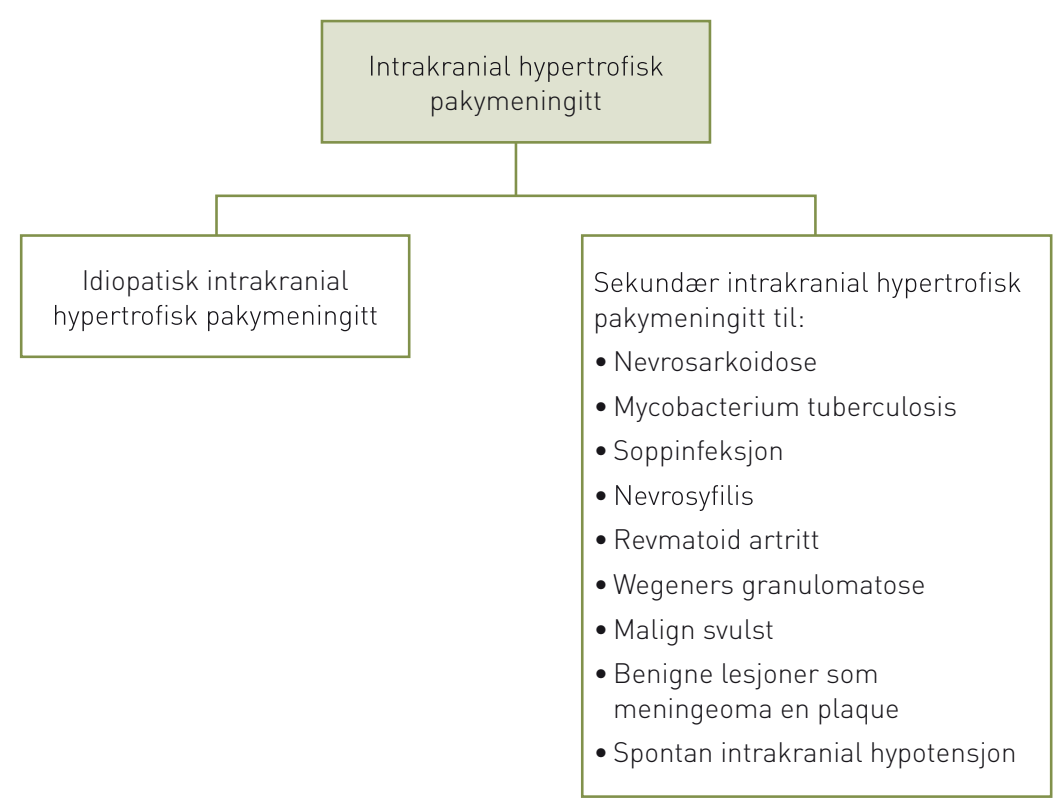

Figur 3 Etiologi ved intrakranial hypertrofisk pakymeningitt (2, 3)

lingsrunder. Sykdommen er i remisjon, pasienten er symptomfri og tilbake i full jobb.

\section{Diskusjon}

Intrakranial hypertrofisk pakymeningitt kan involvere skallebeinet, det perikraniale bløtvevet og en sjelden gang det cerebrale parenkymet (når inflammatoriske celler infiltrerer gjennom det Virchow-Robinske rom) (9). Pakymeningeal fortykkelse kan være diffus eller fokal/nodulær. Den nodulære typen kan inndeles $i$ to hovedgrupper ut fra lokalisasjonen $(4,13)$. Den første gruppen inkluderer tilfeller lokalisert i området fra parasellaris og sinus cavernosus til fissura orbitalis superior, og affiserer ofte 2.-6. hjernenerve og det supraklinoidale carotissegmentet. Den andre gruppen involverer overgangen mellom falx cerebri og tentorium cerebelli samt clivus, med affeksjon av 5. og 7.-10. hjernenerve (13).

Intrakranial hypertrofisk pakymeningitt av den cerebrale konveksiteten, som kan imitere konveksitetsmeningeoma, forekommer i ca. $15 \%$ av de fokale tilstandene (2). Hjernenerveutfall skyldes at fortykkede pakymeninger komprimerer nervene ved deres utløp i skallens foramina (14). En slik ekstern stenose ved skallebasisen kan også føre til okklusjon av a. carotis interna, med kortikale utfall som følge (15). Slike lesjoner gir masseeffekt, men den inflammatoriske perivaskulære infiltrasjonen spiller også en viktig rolle i den kortikale irritative symptomatologien $(9,16)$. Intrakranial hypertrofisk pakymeningitt kan en sjelden gang også føre til okklusjon av venesinus og obstruktiv hydrocephalus (15). Spinal hypertrofisk pakymeningitt er sjelden. Cervikale og torakale regioner er trolig mest affisert, og den meningeale fortykkelsen forårsaker radikulomyelopati (17).

Patogenesen til hypertrofisk pakymenin- gitt er uklar. Patologi- og laboratoriedata antyder en nær assosiasjon med autoimmune sykdommer som Wegeners granulomatose, revmatoid artritt og bindevevssykdommer, og det har vært diskutert om tilstanden er forårsaket av autoimmun systemisk inflammasjon (18). Blodprøver viser vanligvis høy senkningsreaksjon $(3,5$, $8,18)$, og en studie fra Japan viste lett til moderat forhøyet CRP i omtrent halvparten av tilfellene (18). Det er beskrevet flere tilfeller med positive antinukleære antistoff (ANA), revmatoid faktor (RF) og p-ANCA (18). Prøver av cerebrospinalvæsken avdekker pleocytose hos $30-70 \%$ av pasientene $(5,8$, 18) og økt totalprotein hos ca. $80 \%$ (18). Åpningstrykket ved lumbalpunksjon er vanligvis normalt, men kan være forhøyet (18).

Nevroradiologisk undersøkelse spiller en sentral rolle i evalueringen av sykdommen. Imidlertid kan det ta to år før det tilkommer signifikante bildediagnostiske funn (19). CT-bilder avslører hyperintense durale lesjoner med homogen kontrastladning, men i enkelte tilfeller, for eksempel ved lite uttalt dural fortykkelse, påvises det ikke unormale funn (18). MR-undersøkelse er den beste

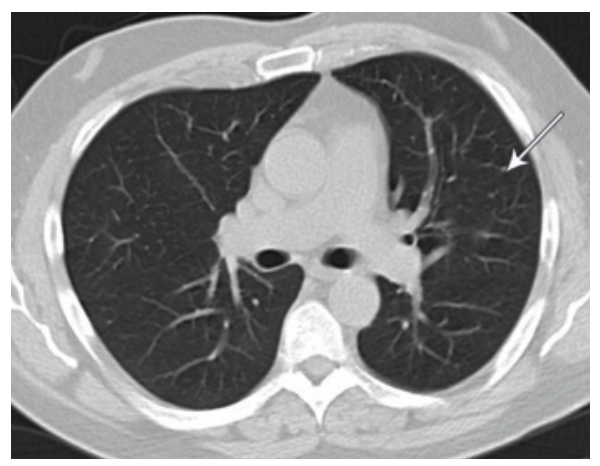

Figur 4 CT thorax. Små uspesifikke nodulære fortetninger i venstre overlapp 
metoden til å identifisere lesjonene og utelukke andre sykdomsprosesser. MR-funn er karakteristiske og viser forskjellige grader av lesjonens inflammatoriske mønster $(5,8)$. T1-vektede bilder viser isodens eller hypodens fortykket dura $(6,8,9,13)$ med intens forsterkning etter injeksjon av paramagnetisk kontrastmiddel, grunnet inflammatorisk reaksjon i pakymeningene. Dura mater opptrer hypointenst på T2-vektede bilder, i enkelte tilfeller omgitt av en hyperintens rand av lesjonen $(8,9,13,19)$. Det sentrale hypodense området er relatert til en fibrøs prosess, mens den perifere hyperintensiteten skyldes aktiv inflammatorisk reaksjon (9, 13). Bruk av gadolinium er viktig for å bedømme den meningeale ladningen, som kan brukes til å skille mellom pakymeningitt og leptomeningitt. MR-funn kan også gi en indikasjon på det kliniske forløpet. Diffus og homogen fortykkelse av dura og godt definerte T2-vektede randsoner er assosiert med kort klinisk forløp og god prognose. Hypodens hypertrofisk hjernehinne på T2-vektede serier, uten hyperdens rand og med dishomogen kontrastladning er forbundet med kroniske tilstander og ugunstig prognose (8).

For å utelukke sekundær intrakranial hypertrofisk pakymeningitt bør utredningen inkludere meningeal biopsi $(2,18,20)$. Ifølge Bang og medarbeidere (8) og Goyal og medarbeidere (14) skal det ved diffus eller skallebasislokalisert intrakranial hypertrofisk pakymeningitt være mulig å stille diagnosen på klinisk grunnlag (positiv MR og effektiv kortikosteroidterapi), mens det ved nodulær intrakranial hypertrofisk pakymeningitt over konveksiteten og ved tvilsomme tilfeller er essensielt med biopsi for å kunne utelukke meningeom og andre neoplasmer. Kupersmith og medarbeidere (3) anbefaler invasiv diagnostikk ved klinisk eller radiologisk forverring under pågående behandling. Histopatologisk undersøkelse av fortykket dura viser uspesifikk inflammatorisk reaksjon i ulike utviklingsfaser, med fibroblastisk infiltrasjon av nøytrofile celler, lymfocytter og plasmaceller $(4,16)$. Vaskulitt og granulomatøse forandringer er beskrevet $(17,21)$.

Det er ingen konsensus om den terapeutiske tilnærmingen ved intrakranial hypertrofisk pakymeningitt. Spontan resolusjon av symptomer, funn og meningeal fortykkelse er beskrevet (22). Kortikosteroidterapi er ofte effektivt til å forbedre symptomer og funn samt til å stanse sykdomsutviklingen. Ved resistens eller residiv under nedtrapping kan det legges til andre immundempende midler som cyklofosfamid, metotreksat eller azatioprin (13). Radioterapi og kirurgisk fjerning av affisert vev er blitt anvendt (3). Grunnet risiko for irreversibel skade av nervesystemet ved kompressiv myelopati synes tidlig kirurgisk intervensjon å være sentralt når steroidbehandlingen ikke forhindrer progresjon av symptomer ved spinal hypertrofisk pakymeningitt (17).

Pasienten har gitt samtykke til at artikkelen blir publisert.

\section{Agnes Balint Bjørke (f. 1978)}

er spesialist i nevrologi og overlege ved Nevrologisk avdeling, Drammen Sykehus, Vestre Viken

Forfatter har fylt ut ICMJE-skjemaet og oppgir ingen interessekonflikter.

\section{Christoph Michael Wahl (f. 1969)}

er lege og spesialist i nevrologi fra Tyskland. Han er overlege ved Avdeling for nevrologi og Nevromuskulært kompetansesenter, Universitetssykehuset i Troms $\varnothing$ og er tilknyttet nevromuskulær forskningsgruppe ved Institutt for klinisk medisin ved Universitetet i Troms $\varnothing$. Forfatter har fylt ut ICMJE-skjemaet og oppgir følgende interessekonflikter: Han har mottatt honorar for forelesninger fra Pfizer, men dette er ikke knyttet til denne artikkelen.

\section{Synøve Kalstad (f. 1964)}

er spesialist i revmatologi og overlege ved Revmatologisk avdeling, Universitetssykehuset Nord-Norge.

Forfatter har fylt ut ICMJE-skjemaet og oppgir ingen interessekonflikter.

\section{Litteratur}

1. Charcot JM, Joffroy A. Deux cas d'athrophie musculaire progressive avec lésions de la substance gris et des faisceaux antériolatéraux de la melle épinière. Arch Physiol Norm Pathol 1869; 2: $354-67,629-49,744-69$

2. D’Andrea G, Trillò G, Celli P et al. Idiopathic intracranial hypertrophic pachymeningitis: two case reports and review of the literature. Neurosurg Rev 2004; 27: 199-204

3. Kupersmith MJ, Martin V, Heller G et al. Idiopathic hypertrophic pachymeningitis. Neurology 2004; 62 686-94.

4. Deprez M, Born J, Hauwaert C et al. Idiopathic hypertrophic cranial pachymeningitis mimicking multiple meningiomas: case report and review of the literature. Acta Neuropathol 1997; 94: 385-9.

5. Parney IF, Johnson ES, Allen PB. «ldiopathic» cranial hypertrophic pachymeningitis responsive to antituberculous therapy: case report. Neurosurgery 1997; 41: 965-71

6. Nishioka H, Ito H, Haraoka J et al. Idiopathic hypertrophic cranial pachymeningitis with accumulation of thallium-201 on single-photon emission CT. AJNR Am J Neuroradiol 1998; 19: 450-3.

7. Naffziger HC, Stern WE. Chronic pachymeningitis report of a case and review of the literature. Arch Neurol Psychiatry 1949; 62: 383-411.

8. Bang OY, Kim DI, Yoon SR et al. Idiopathic hypertrophic pachymeningeal lesions: correlation between clinical patterns and neuroimaging characteristics. Eur Neurol 1998; 39: 49-56.

9. Nishizaki T, Iwamoto F, Uesugi S et al. Idiopathic cranial pachymeningoencephalitis focally affecting the parietal dura mater and adjacent brain parenchyma: case report. Neurosurgery 1997; 40: $840-3$, discussion 843.

10. Phanthumchinda K, Sinsawaiwong S, Hemachudha T et al. Idiopathic hypertrophic cranial pac hymeningitis: an unusual cause of subacute and chronic headache. Headache 1997; 37: 249-52.

11. Wouda EJ, Vanneste JA. Aspecific headache during 13 years as the only symptom of idiopathic hypertrophic pachymeningitis. J Neurol Neurosurg Psychiatry 1998; 64: 408-9.

12. Wang YJ, Fuh JL, Lirng JF et al. Headache profile in patients with idiopathic hypertrophic cranial pachymeningitis. Headache 2004; 44: 916-23

13. Hatano N, Behari S, Nagatani T et al. Idiopathic hypertrophic cranial pachymeningitis: clinicoradiological spectrum and therapeutic options. Neurosurgery 1999: 45: 1336-42, discussion 1342-4.

14. Goyal M, Malik A, Mishra NK et al. Idiopathic hypertrophic pachymeningitis: spectrum of the disease. Neuroradiology 1997; 39: 619-23.

15. Willing SJ, Broghamer W. Internal carotid artery occlusion due to idiopathic cranial pachymeningitis. AJNR Am J Neuroradiol 1992; 13: 1594-6.

16. Kadoya C, Soejima T, Yamada H et al. Pachymeningoencephalitis: case report. Neurosurgery 1993: 33: $131-4$

17. Mikawa Y, Watanabe R, Hino Y et al. Hypertrophic spinal pachymeningitis. Spine 1994; 19: 620-5.

18. Riku S, Kato S. Idiopathic hypertrophic pachymeningitis. Neuropathology 2003; 23: 335-44.

19. Mamelak AN, Kelly WM, Davis RL et al. Idiopathic hypertrophic cranial pachymeningitis. Report of three cases. J Neurosurg 1993; 79: $270-6$.

20. Bosman T, Simonin C, Launay D et al. Idiopathic hypertrophic cranial pachymeningitis treated by oral methotrexate: a case report and review of literature. Rheumatol Int 2008; 28: 713-8.

21. Nagashima T, Maguchi S, Terayama Y et al. PANCA-positive Wegener's granulomatosis presenting with hypertrophic pachymeningitis and multiple cranial neuropathies: case report and review of literature. Neuropathology 2000; 20: 23-30.

22. Nishio S, Morioka T, Togawa A et al. Spontaneous resolution of hypertrophic cranial pachymeningitis. Neurosurg Rev 1995; 18: $201-4$.

Mottatt 17.6. 2011, første revisjon innsendt 13.11 2011, godkjent 15.12. 2011. Medisinsk redaktør Erlend Aasheim. 